\title{
Beverage consumption habits "24/7" among British adults: association with total water intake and energy intake
}

Sigrid Gibson ${ }^{1 *}$ and Susan M Shirreffs ${ }^{2}$

\begin{abstract}
Background: Various recommendations exist for total water intake (TWI), yet it is seldom reported in dietary surveys. Few studies have examined how real-life consumption patterns, including beverage type, variety and timing relate to TWI and energy intake (EI).
\end{abstract}

Methods: We analysed weighed dietary records from the National Diet and Nutrition Survey of 1724 British adults aged 19-64 years (2000/2001) to investigate beverage consumption patterns over 24 hrs and 7 days and associations with TWI and El. TWI was calculated from the nutrient composition of each item of food and drink and compared with reference values.

Results: Mean TWI was $2.53 \mathrm{~L}$ (SD 0.86) for men and $2.03 \mathrm{~L}$ (SD 0.71) for women, close to the European Food Safety Authority "adequate Intake" (Al) of $2.5 \mathrm{~L}$ and $2 \mathrm{~L}$, respectively. However, for $33 \%$ of men and $23 \%$ of women TWI was below Al and TWl:El ratio was $<1 \mathrm{~g} / \mathrm{kcal}$. Beverages accounted for $75 \%$ of TWl. Beverage variety was correlated with TWI ( $r$ 0.34) and more weakly with El ( $r$ 0.16). Beverage consumption peaked at 0800 hrs (mainly hot beverages/ milk) and 2100 hrs (mainly alcohol). Total beverage consumption was higher at weekends, especially among men. Overall, beverages supplied 16\% of El (men 17\%, women 14\%), alcoholic drinks contributed 9\% (men) and $5 \%$ (women), milk 5-6\%, caloric soft drinks 2\%, and fruit juice $1 \%$.

In multi-variable regression (adjusted for sex, age, body weight, smoking, dieting, activity level and mis-reporting), replacing $100 \mathrm{~g}$ of caloric beverages (milk, fruit juice, caloric soft drinks and alcohol) with $100 \mathrm{~g}$ non-caloric drinks (diet soft drinks, hot beverages and water) was associated with a reduction in El of $15 \mathrm{kcal}$, or $34 \mathrm{kcal}$ if food energy were unchanged. Using within-person data (deviations from 7-day mean) each $100 \mathrm{~g}$ change in caloric beverages was associated with $29 \mathrm{kcal}$ change in El or $35 \mathrm{kcal}$ if food energy were constant. By comparison the calculated energy content of caloric drinks consumed was $47 \mathrm{kcal} / 100 \mathrm{~g}$.

Conclusions: TWI and beverage consumption are closely related, and some individuals appeared to have low TWI. Energy from beverages may be partly compensated. A better understanding of interactions between drinking and eating habits and their impact on water and energy balance would give a firmer basis to dietary recommendations.

Keywords: Water intake, Energy, Beverage consumption, Adults, Dietary patterns

\footnotetext{
* Correspondence: sigrid@sig-nurture.com

${ }^{1}$ Sig-Nurture Ltd., Guildford, Surrey Gu1 2TF, UK

Full list of author information is available at the end of the article
} 


\section{Introduction}

Water is arguably the most critical nutrient, as its absence can be lethal within a few days [1-3]. To promote adequate water intake at the population level, several countries and transnational authorities have developed water intake recommendations based on national estimates of water intake [4-6]. In the UK, data on total water intake (TWI) is not normally published in national survey reports and there is currently no Dietary Reference Value. The main purpose of this study was to quantify TWI and its relation to patterns of beverage consumption and then to explore associations between types of beverage consumed and the intake of water and energy. It has been estimated from studies in Europe and the USA that around $70 \%-80 \%$ of TWI comes from beverages of various types (including water, tea and coffee, milk, soft drinks, juice and alcoholic drinks), with the remainder contributed by water in food [4,7], and we expected the British population would have a similar pattern. Beverages are widely available in developed societies, where tap water is essentially free, but there are nevertheless concerns that some people may not be consuming sufficient fluid for optimal health and some people may be overconsuming. Children, elderly or infirm people, and those working in hot environments, are some of those most vulnerable to the effects of dehydration, but many adults may also be inadequately hydrated at some time. Unfortunately, hydration status is rarely measured in epidemiological studies and this hampers attempts to assess the adequacy of water intakes at a population level. However, guidelines have been established to determine how much water humans require (on average) to avoid dehydration and to optimise physical and psychological function.

In 2005, the Food and Nutrition board of the Institute of Medicine (IOM) published adequate intake (AI) values for TWI in temperate climates [5]. The AI for total water (from a combination of drinking water, beverages, and food) was set based on the median total water intake from US survey data. For young men and women (19-30 years) this is $3.7 \mathrm{~L}$ and $2.7 \mathrm{~L}$ per day, respectively. These recommended intakes are based on median intakes of generally healthy individuals who are adequately hydrated, but the report pointed out that individuals can be adequately hydrated at levels below, as well as above, the AIs provided. The American AIs exceed those of other authorities, while the recent recommendations produced by the European Food Safety Authority (EFSA) in 2010 are the most conservative to date, at $2.0 \mathrm{~L}$ per day for adult females and 2.5 L per day for adult males [4].

Limited data exist on daily water intake in other countries, and comparison is sometimes hampered by different methods of definition and data collection [8]. In the UK, TWI is not currently quoted in the published reports but the mean value has been calculated as $2494 \mathrm{~g} /$ day among adults aged 19-64 y in 2008/9 [9]. Average water intakes in other European countries appear to be broadly similar to those in the UK (e.g. mean $2461 \mathrm{ml} /$ day in Sweden [10]), or else lower than the UK, (e.g. mean intake $1984 \mathrm{ml} / \mathrm{d}$ in France [11]; $2039 \mathrm{ml} /$ day in Germany [12]; $2222 \mathrm{ml} / \mathrm{d}$ in the Netherlands [13]). Reported intakes of total water in North America are considerably higher than in Britain and Europe. In 2005-2006, American adults participating in the National Health and Nutrition Examination Surveys (NHANES) reported consuming $3.18 \mathrm{~L}$ of total water within the previous 24 hours [7], slightly less than the 3.35 L reported in 1999-2004.

While all beverages support hydration by virtue of their high water content, many also supply calories. Excessive consumption of caloric beverages has been widely viewed as contributing to the obesity epidemic [14,15], although systematic reviews have highlighted the need for better randomised controlled trials, in order to demonstrate a causal effect [16,17]. The main putative mechanism involves reduced satiety and incomplete compensation for calories ingested in liquid form [18]. According to this theory, so-called "liquid calories" are more likely than solid calories to result in passive overconsumption and excess energy intake [19]. There are, however, few studies that have examined relationships between beverage consumption patterns and energy intake in the British population, apart from the recent paper by $\mathrm{Ng}$ et al. [9], which reported that the proportion of energy from beverages changed very little between 1986 and 2008/9, although there were some shifts between sources. Our paper differs in scope, focusing on consumption over 24 hours and 7 days of the week and comparing water intakes, in men and women with reference values.

The National Diet and Nutrition Survey database provides what is probably the best source of detailed information on the diets of normal individuals in Britain [20,21]. In 2008 the survey adopted a new method, collecting data via a (non-weighed) diet record over 4 days, in place of the former weighed record over 7 days, in 2000/2001. The latter, slightly older, data provide the opportunity to study variation over days of the week and may give a better indication of participants' usual intake. The food records list the weight in grams of each item of food and drink consumed (including tap water) for each of the 1724 participants (12,068 person-days of data), while the nutrient database includes the water, energy and nutrient content of each item. Time of consumption is also recorded, providing a rich resource for exploring patterns of consumption (timing, frequency, variety etc.) and linking this with personal data. Using raw data from the NDNS we attempted to address the following questions:

1) Is the UK adult population consuming adequate amounts of total water? 
2) How does beverage consumption vary by age and gender, day of the week and time of day and is this related to total water intake?

3) Is the variety of beverages consumed a positive predictor of total water intake?

4) How much energy do beverages contribute to the UK diet and in what proportion?

5) Is energy in liquid form (i.e. from beverages) positively associated with total energy intake?

\section{Methods}

\section{The survey}

The National Diet and Nutrition Survey: adults aged 19 to 64 years, (NDNS) is a nationally representative survey of the diet and health of adults living in private households in Great Britain in 2000/2001 [21]. It was commissioned jointly by the Department of Health and the Food Standards Agency and ethical approval was obtained via the normal channels. Fieldwork was conducted over a 12month period in 2000/2001 to cover any seasonality in eating behavior and in the nutrient content of foods. Overall, $61 \%$ of the eligible sample $(n=3704)$ completed the dietary interview (responding sample, $n=2,251$ ) and $77 \%$ of those who completed the dietary interview completed a full seven-day weighed dietary record (diary sample, $\mathrm{n}=1724$, representing 12068 person-days of data) [21]. There was no evidence of serious non-response bias, although inevitably surveys of this type favour willing participants whose diets may be less extreme, or less variable day to day.

Respondents were asked to keep a weighed record of all food and drink consumed, both in and out of the home. Each respondent was issued with a set of digital food scales and instructed how to weigh and record items in two diaries, "Home" and "Eating out". A description of each item was recorded, including the brand name of the product and if appropriate, the method of preparation. Also recorded was the time (to the nearest 5 minutes) and location. Everything consumed by the respondent had to be recorded, including drinks of water and medications and supplements. Respondents were asked to weigh everything they could as separate items in order that the nutrient composition of each could be calculated. Recipes for all home-made dishes were collected. Where it was not possible to weigh the food, respondents were asked to record as much information as possible, particularly the portion size and an estimate of any leftover and, for meals out, price and place of purchase. In certain circumstances duplicate portions were purchased for weighing. Interviewers visited workplace canteens to collect information on portion sizes, cooking methods and ingredients.

Each interviewer called back 24 hours after placing the diaries to check that the items were being recorded correctly, to give encouragement and re-motivate where appropriate. Further visits were included as necessary and any apparent omission of meals or snacks was probed. Interviewers were trained in coding the diaries and could therefore identify the level of detail needed for different items. As fieldwork progressed, new codes were added for homemade dishes and items appearing in the diaries. Interviewers were asked to assess the quality of the dietary record and how far they thought it reflected the respondent's normal diet. Further detailed checks were carried out for completion and consistency at the Office for National Statistics and then information from the dietary records was linked to the Nutrient Databank. This holds information on 56 nutrients, including water content, for each of the $6000+$ food codes.

Respondents also completed a diary detailing the time spent on specified activities, and the intensity of activity, over the same 7 days as the dietary record. A physical activity score was calculated by multiplying the duration of each activity by the metabolic equivalent value (MET) for activities of that intensity. The average MET score represents an estimate of hourly energy expenditure per $\mathrm{kg}$ of body weight. Body weight was measured by trained personnel at the nurse visit after completion of diaries. Further details are given in Appendix D of the published report [22].

\section{Data preparation and analysis}

Computerised raw data files and documentation from this survey, comprising weighed food records, questionnaires and biochemical and medical data, were obtained under license from the UK Data Archive (http://www. data-archive.ac.uk) and analysed using IBM $^{\circledR}$ SPSS statistics v19 (SPSS IBM Inc Chicago, Illinois, USA).

Data were first analysed at the level of the individual food diaries, comprising weighed records for 12068 days (7 days for each survey respondent). Individual food items are recorded both with their original food codes and a higher level classification into 115 food groups for the published reports. The present analysis focused on total water intake (TWI) of all food and drink, as determined from food composition tables in the database. Metabolic water (water derived from oxidation of substrates) was not included as the focus was on comparison with dietary water requirements. Water in coffee or tea was coded as coffee/tea, while water for diluting concentrated soft drinks was coded as soft drink. Bottled water was coded separately from tap water. Milk includes all liquid milk, including that in tea and coffee, and milk consumed with cereal. Discretionary table sugar added to beverages was counted as food, rather than drink, as it was not possible to differentiate sugar use in drinks from sugar sprinkled on cereal or fruit consumed at the same time. For this project beverages were combined into 8 categories 
for further analysis: hot beverages (tea/coffee); milk; 100\% fruit juice; caloric soft drinks (including sodas, juice drinks, sports and energy drinks); diet soft drinks; alcoholic drinks (including beer, cider, wine, spirits, alcopops); bottled water; and tap water. To investigate trends over the day, consumption occasions were aggregated into hourly intervals and into 5 periods, approximately corresponding to breakfast ( $<1000 \mathrm{hrs})$, lunch ( $>1000$ to $1400 \mathrm{hrs}$ ), afternoon (>1400 to $1800 \mathrm{hrs}$ ), evening (1800 to $2200 \mathrm{hrs)}$ and night (>2200 to 0200). Mean daily consumption, calculated over 7 days, was used to compare between individuals. TWI was compared with EFSA Dietary Reference Values (DRV) for Adequate Intake of Water (AI) for adult men and women of $2.5 \mathrm{~L}$ and $2.0 \mathrm{~L}$, respectively [4]. The EFSA value for adequate intake is more conservative than other recommendations from WHO or IOM [5]. Nordic and German speaking countries take the approach that water intake is considered inadequate when it is less than $1 \mathrm{~g}$ per kilocalorie of energy requirement [4]. Therefore a combined classification (TWI-2), based on dual criteria, (i) the $\mathrm{AI}$, and (ii) the ratio of water intake in grams to energy intake in kcal [4] was used to provide a more conservative estimate of the proportion of adults consuming low amounts of water (although with no implication of inadequate hydration status).

\section{Statistical analyses}

Univariate analyses were carried out for men and women separately because of known differences in water consumption and recommended intakes. Crude differences in TWI and beverage consumption between groups were assessed using T-tests with Bonferroni correction for multiple comparisons. Non-parametric tests were used for variables that were markedly non-normal. Chi-square tests were used for categorical variables. All tests were 2-tailed and $\mathrm{P}<0.05$ taken as indicating statistical significance.

Multivariate analyses included adjustment for sex, age, bodyweight, smoking, dieting, physical activity level and mis-reporting (a recognized problem in dietary surveys with the potential to affect results) [23]. We attempted to adjust for implausible energy reporting using individuals' ratio of energy intake (EI) to basal metabolic rate (BMR) [24] and applied Goldberg cut-offs corresponding to confidence limits of plausible intake based on a 7 day diet record at a physical activity level (PAL) of 1.55 [25]. Adults whose reported EI was $<1.05$ times their BMR were classified as under-reporters, while those with reported EI $>2.28$ times $\mathrm{BMR}$ were classified as overreporters. Rather than exclude misreporters entirely, which can introduce bias, we included the classification variable in the analysis.

Analysis of covariance was used initially to examine how energy intake varied as the proportion of "liquid calories" increased (compared with food calories); covariates in the model were: sex, age, bodyweight, smoking, dieting, misreporting and physical activity. Multiple linear regression was used to estimate the effect on energy intake of varying the type of beverages consumed, whilst controlling for the effect of confounders. The effect of substituting non-caloric beverages by caloric beverages was estimated by including caloric beverages (as percentage of total beverage weight) as the main independent variable, with total beverage weight $(\mathrm{g})$ held constant. This necessarily implies an equal and opposite change in other beverages. A further model included energy from food, thus disallowing compensation (reduction of food calories). Finally, we used the within-person daily consumption data to explore the effect of changes in consumption day-to-day, with each person acting as their own control. The independent variables in this analysis were all difference variables (deviation from the subject's 7 day mean, deviation in total beverage consumption from subject mean) with deviation in energy intake as the outcome.

\section{Table 1 Descriptive statistics of the NDNS sample}

\begin{tabular}{|c|c|c|c|c|c|}
\hline & & & Male & Female & Total \\
\hline & & Count & 766 & 958 & 1724 \\
\hline \multicolumn{6}{|l|}{ Age group } \\
\hline & $<35 y$ & $\%$ & $32 \%$ & $33 \%$ & $32 \%$ \\
\hline & $35<50 y$ & $\%$ & $39 \%$ & $38 \%$ & $39 \%$ \\
\hline & $50 y+$ & $\%$ & $29 \%$ & $29 \%$ & $29 \%$ \\
\hline \multicolumn{6}{|l|}{ Social class } \\
\hline & non-manual & $\%$ & $53 \%$ & $68 \%$ & $61 \%$ \\
\hline & manual & $\%$ & $47 \%$ & $32 \%$ & $39 \%$ \\
\hline \multicolumn{6}{|l|}{ Smoking habit } \\
\hline & non-smoker & $\%$ & $69 \%$ & $67 \%$ & $68 \%$ \\
\hline & smoker & $\%$ & $31 \%$ & $33 \%$ & $32 \%$ \\
\hline \multicolumn{6}{|c|}{ On a diet to lose weight } \\
\hline & No & $\%$ & $89 \%$ & $75 \%$ & $81 \%$ \\
\hline & yes & $\%$ & $12 \%$ & $25 \%$ & $19 \%$ \\
\hline \multirow[t]{2}{*}{ Weight (kg) } & & Mean & 84 & 69 & 76 \\
\hline & & SE & 1 & 1 & 0 \\
\hline \multirow[t]{2}{*}{ Height (cm) } & & Mean & 176 & 162 & 168 \\
\hline & & SE & 0.3 & 0.2 & 0.2 \\
\hline \multirow[t]{2}{*}{$\mathrm{BMl}-\mathrm{kg} / \mathrm{m} 2$} & & Mean & 27.2 & 26.5 & 26.8 \\
\hline & & SE & 0.2 & 0.2 & 0.1 \\
\hline \multicolumn{6}{|c|}{ BMI class: normal, overweight or obese } \\
\hline & normal weight & $\%$ & $32 \%$ & $46 \%$ & $40 \%$ \\
\hline & overweight & $\%$ & $44 \%$ & $33 \%$ & $38 \%$ \\
\hline & obese & $\%$ & $24 \%$ & $21 \%$ & $22 \%$ \\
\hline
\end{tabular}




\section{Results}

\section{Description of the survey sample}

Survey respondents ranged from 19 to 64 years (mean 42 years), with slightly more women than men completing dietary records (Table 1). Around one third were current smokers and $25 \%$ of women ( $12 \%$ of men) were on a diet to lose weight. Obesity measures were representative of the UK adult population in 2000, with $60 \%$ overweight or obese.

\section{Total water intake (TWI) and association with beverage consumption}

Total water intake from all sources averaged $2.5 \mathrm{~L}$ and $2.0 \mathrm{~L}$ and men and women, respectively (Figure 1, Table 2). This concords with the estimated AI set by EFSA [4]. Beverages accounted for $75 \%$ of total water and $66 \%$ of the total weight of food and drink consumed. Mean beverage consumption was $1779 \mathrm{~g} / \mathrm{d}$ (2012 g/d among men, $1593 \mathrm{~g} / \mathrm{d}$ among women). Hot drinks (principally tea and coffee) were consumed by $97 \%$ of men and women, similarly for milk (95-96\%) (Figure 2). Among men, alcoholic drinks were more popular than tap water (79\% vs. $60 \%$ consumed, respectively), while $66 \%$ of women consumed alcohol and $73 \%$ drank tap water. More than half the sample drank caloric soft drinks at least once during the week, while less than half drank fruit juice, diet soft drinks or bottled water.

Tea and coffee accounted for over $40 \%$ of the total daily weight of beverages while milk provided an additional 12\% (232 g/d for men, $202 \mathrm{~g} / \mathrm{d}$ for women) (Table 2). Men consumed much higher quantities of alcoholic drinks (mean 501 vs. 141 g/d for women; $\mathrm{P}<$ 0.0001 ) and slightly more caloric soft drinks (mean 129 vs. $95 \mathrm{~g} / \mathrm{d}, \mathrm{P}=0.001)$. By contrast, women consumed more tap water (243 vs. $187 \mathrm{~g} / \mathrm{d}$ for men; $\mathrm{P}<0.0001)$ and diet soft drinks (93 vs. $82 \mathrm{~g} / \mathrm{d}, \mathrm{P}=0.002$ ). Bottled water and fruit juice were consumed in small amounts by both sexes $(<60 \mathrm{~g} / \mathrm{d})$. Younger men and women consumed less hot beverages and milk, but significantly more soft drinks (both caloric and non-caloric) and alcohol than older adults (Table 3). Mean consumption of caloric soft drinks over the total sample was $110 \mathrm{~g} / \mathrm{d}$ or 2 cans per week, but younger women and men $(<35 y)$ consumed $140 \mathrm{~g} / \mathrm{d}$ and $216 \mathrm{~g} / \mathrm{d}$, respectively. Consumption of alcoholic drinks in these groups averaged $179 \mathrm{~g} / \mathrm{d}$ and $579 \mathrm{~g} / \mathrm{d}$, respectively. Beverages contributed approximately $16 \%$ of total energy overall (men 17\%, women 14\%) and alcohol was a major contributor (9\% of EI for men; 5\% for women) (Table 2).

TWI was very highly correlated with the weight of beverages and water from beverages ( $r$ 0.97) and more weakly correlated with food intake (r 0.29) (Table 4). Hot beverages, tap water and alcohol were most highly correlated with TWI $(r>0.4)$. Alcoholic drinks (r 0.17), caloric soft drinks ( $\mathrm{r}$ 0.15) and milk ( $\mathrm{r}$ 0.14) had the highest correlation with EI, while for tap water and bottled water the coefficients were essentially zero.

\section{Variety of beverages}

Out of a maximum of 8 different types of beverages in our classification, the mean "variety score", averaged over 7 days, was 3.3 for both men and women. Adults consuming fewer than 3 types had lower TWI and were less likely to meet the AI compared with those drinking 3 types or more (mean TWI 1.9 L vs. 2.4 L ; $73 \%$ vs. $43 \%$ below AI). Variety score was positively correlated with TWI (r 0.34, P < 0.0001; Table 4) and with EI (r 0.16, $\mathrm{P}<0.0001$ ), suggesting that beverage variety is an indicator of higher consumption of food and drink generally.

\section{Influence of day of the week}

Total water intake and beverage consumption (g) was significantly higher on Fridays and Saturdays than on other days of the week, especially among men. This
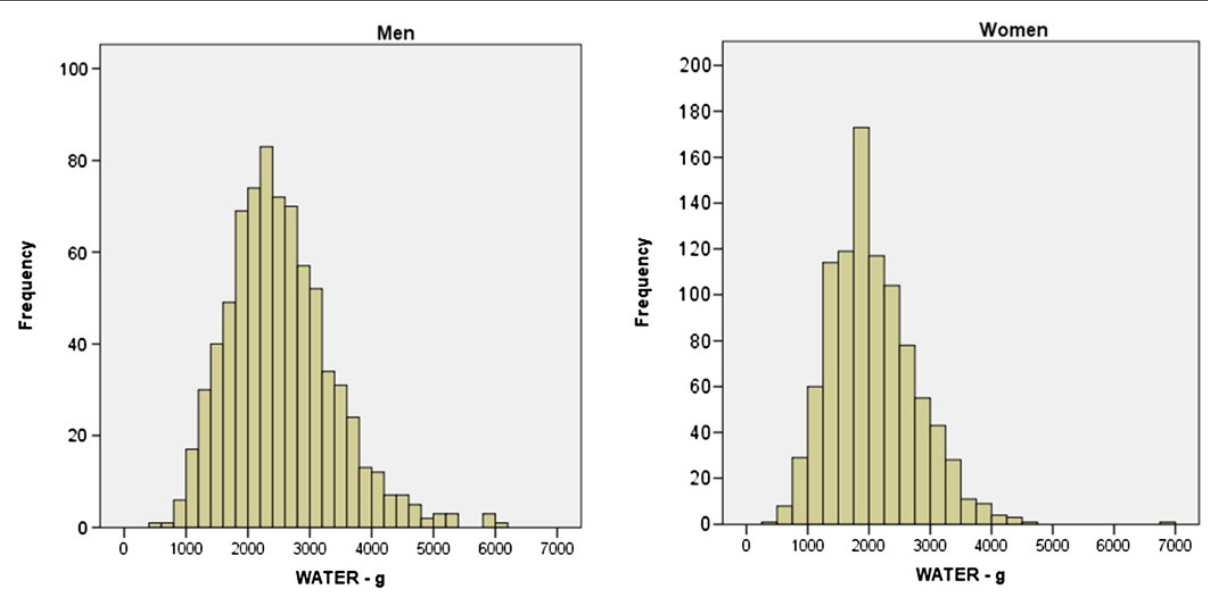

Figure 1 Frequency distribution of total water intake $(g / d)$ over 7 days, by sex. 
Table 2 Contribution of food and beverages to water and energy intake

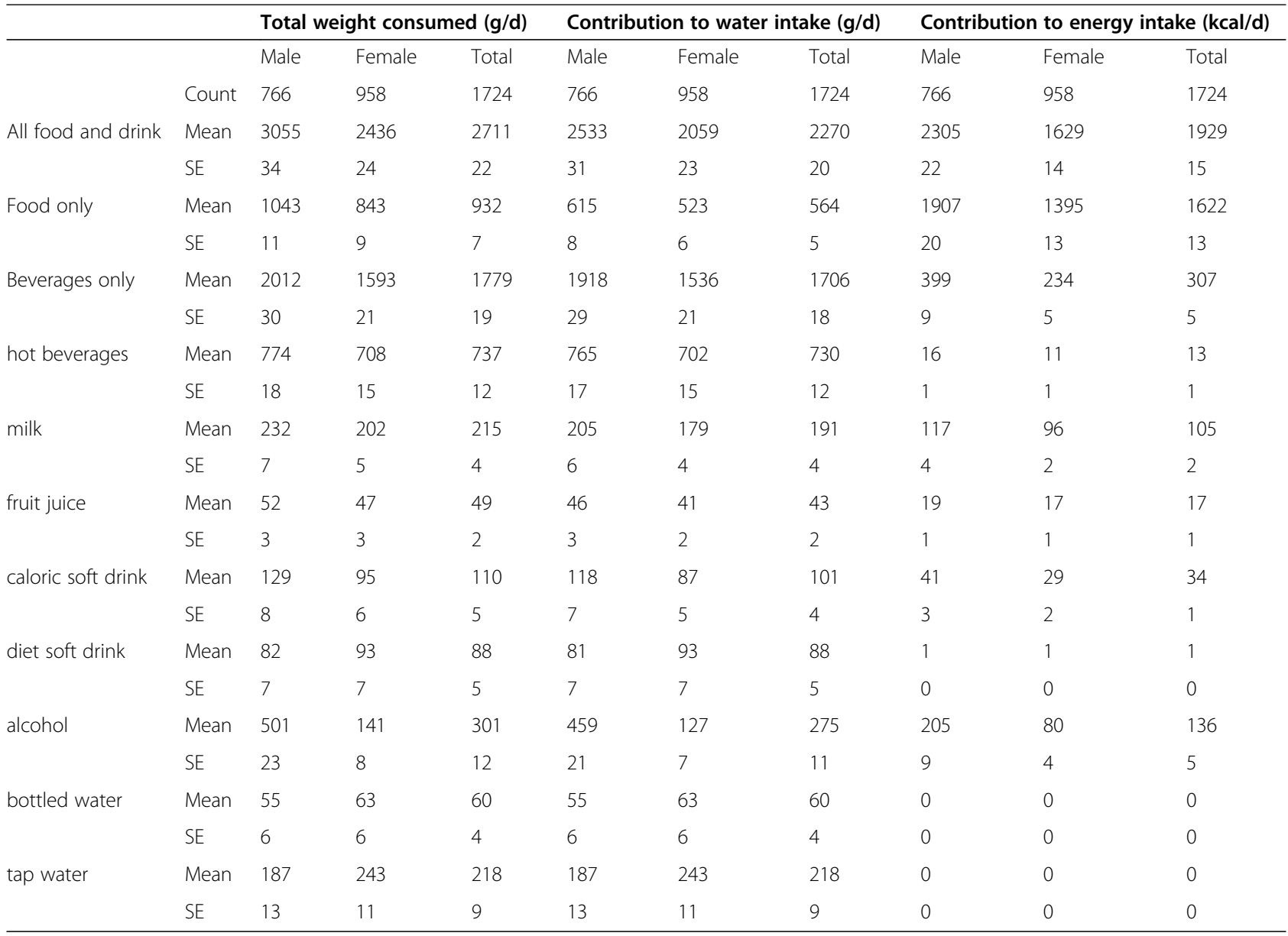

appeared to be attributable to higher consumption of alcoholic drinks at weekends, especially Saturday (Figure 3). Women showed weaker trends, but consumption on weekend days was still twice that on other days of the week. Saturday consumption of alcoholic drinks averaged $262 \mathrm{~g}$ among women and $949 \mathrm{~g}$ among men. Smaller differences in the opposite direction were observed for hot beverages and water. Consumption of soft drinks and fruit juice did not vary greatly by day of the week.

\section{Beverage consumption timeline over $\mathbf{2 4}$ hours}

Beverage consumption peaked at $0800 \mathrm{hrs}$ and $2100 \mathrm{hrs}$ for both men and women. When total consumption of each type of beverage was plotted as a separate line (Figure 4), a peak of hot beverages and milk in the morning and of alcohol in the evening was particularly noticeable, the latter being more marked in men. Other beverages were more evenly spread throughout the day, with slightly higher consumption around lunchtime (1300 hrs) and evening (1900 to 2100 hrs). Additional file 1: Appendix shows the $24 \mathrm{~h}$ time trends of beverage consumption for each day of the week ("24/7").

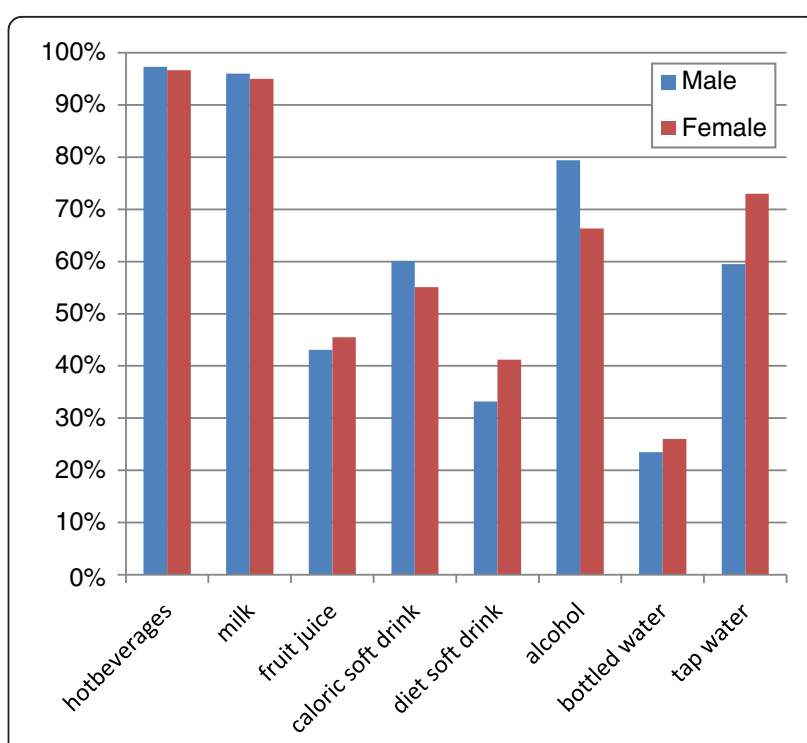

Figure 2 Popularity of beverages (\% consuming over 7 day period). 
Older adults consumed more beverages in the morning, young adults in the evening (Table 5). For example, men aged $50 y+$ consumed on average $30 \%$ of their beverages before $1000 \mathrm{hrs}$, while young men (19-35y) consumed less than 22\%; older men consumed 30\% after 1800 hrs compared to $36 \%$ among younger men. Similar trends (all significant at $\mathrm{p}<0.05$ ) were observed among women. Evening consumption appeared to be driving the higher total beverage consumption on Fridays and Saturdays. Beverages consumed between 0200 hrs and 1000 hrs contributed $25 \%$ of total daily consumption and adults who drank nothing before $1000 \mathrm{hrs}$ only partly compensated for the deficit, having a $16 \%$ lower beverage intake overall (data not shown).
Adults with the highest TWI tended to consume most of their beverages in the evening. Figure 5 illustrates the correlation between timing of consumption (i.e. the proportion of beverage weight consumed in different time periods) and total water intake; the coefficients change from negative in the morning $(\mathrm{r}-0.24$ for men, $\mathrm{r}-0.16$ for women) to positive ( $\mathrm{r} 0.22, \mathrm{r} 0.17$ ) for evening consumption. This effect is partly explained by the dominance of alcohol in evening, as (particularly for men) the correlation coefficients were attenuated when alcohol consuming days were excluded.

In conclusion, alcohol may be a major influence explaining the higher total water intake, higher evening consumption and higher weekend consumption of beverages

Table 3 Total water intake and beverage consumption ( $g / d)$, by age group

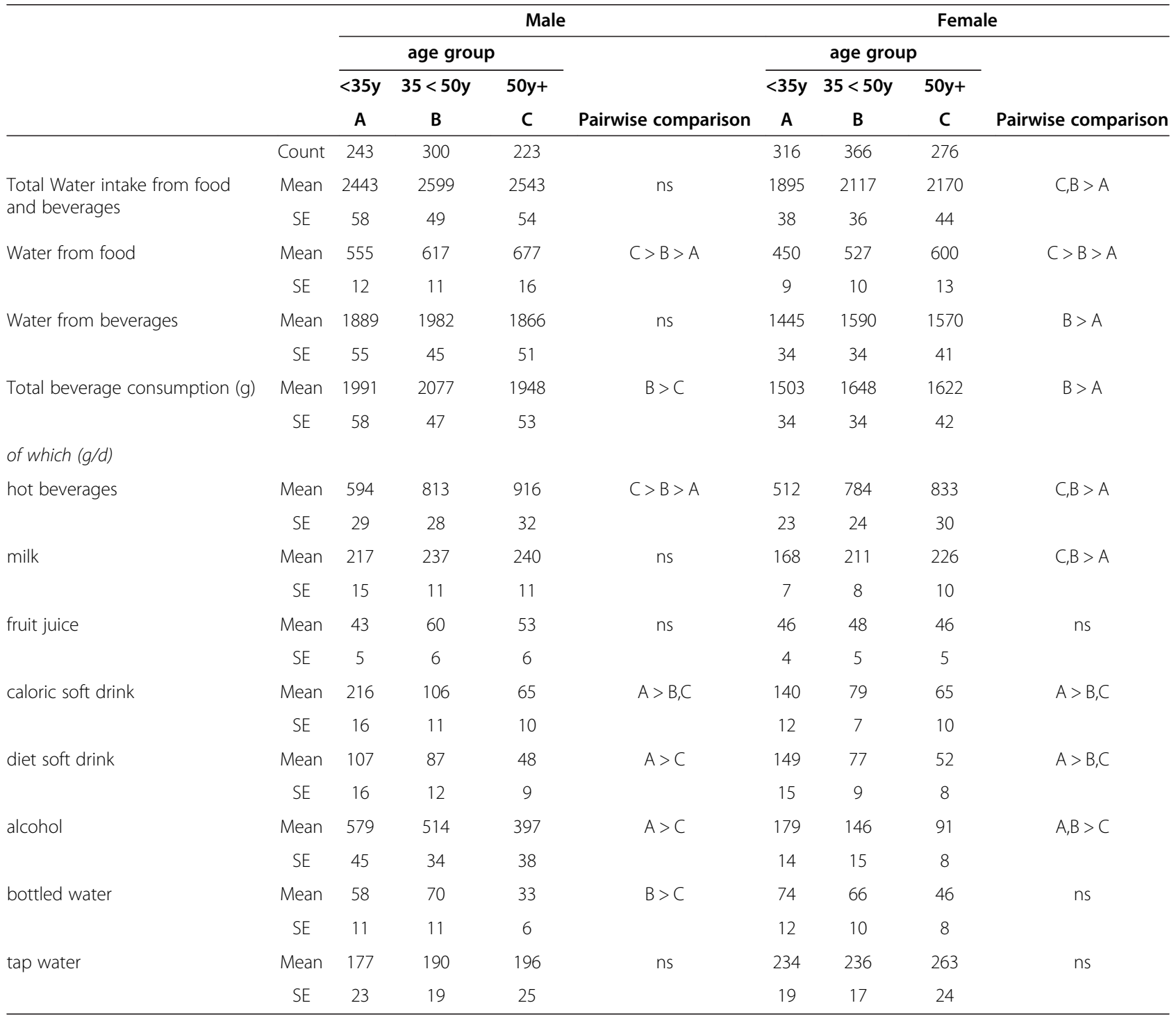


Table 4 Partial Correlations between water intake, energy intake and beverage consumption, (7 day mean data, adjusted for age, gender, bodyweight, smoking, activity level, dieting, misreporting)

\begin{tabular}{|c|c|c|c|c|c|c|c|c|}
\hline & $\begin{array}{l}\text { Total } \\
\text { water* }\end{array}$ & $\begin{array}{c}\text { Water from } \\
\text { beverages }\end{array}$ & $\begin{array}{l}\text { Water } \\
\text { from food }\end{array}$ & $\begin{array}{l}\text { Beverages } \\
\text { weight }\end{array}$ & $\begin{array}{l}\text { Food } \\
\text { weight }\end{array}$ & $\begin{array}{c}\text { Total } \\
\text { energy kcal }\end{array}$ & $\begin{array}{c}\text { Energy from } \\
\text { beverages }\end{array}$ & $\begin{array}{l}\text { Energy } \\
\text { from food }\end{array}$ \\
\hline Total water* & 1.00 & $.97^{* *}$ & $.31^{* *}$ & $.97^{* *}$ & $.29 * *$ & $.35^{* *}$ & $.48^{* *}$ & 1.00 \\
\hline Water from beverages & $.97^{* *}$ & 1.00 & $.07^{* *}$ & $1.00^{* *}$ & $.06^{*}$ & $.28^{* *}$ & $.53^{* *}$ & $.97^{* *}$ \\
\hline Water from food & $.31^{* *}$ & $.07^{* *}$ & 1.00 & $.06^{*}$ & $.96^{* *}$ & $.32^{* *}$ & $-.14^{* *}$ & $.31^{* *}$ \\
\hline Weight of Beverages & $.97^{* *}$ & $1.00^{* *}$ & $.06^{*}$ & 1.00 & 0.04 & $.29^{* *}$ & $.57^{* *}$ & $.97^{* *}$ \\
\hline Weight of food & $.29^{* *}$ & $.06^{*}$ & $.96^{* *}$ & 0.04 & 1.00 & $.51^{* *}$ & $-.20^{* *}$ & $.29^{* *}$ \\
\hline Total energy intake & $.35^{* *}$ & $.28^{* *}$ & $.32^{* *}$ & $.29^{* *}$ & $.51 * *$ & 1.00 & $.31^{* *}$ & $.35^{* *}$ \\
\hline Energy from beverages & $.48^{* *}$ & $.53^{* *}$ & $-.14^{* *}$ & $.57^{* *}$ & $-.20^{* *}$ & $.31^{* *}$ & 1.00 & $.48^{* *}$ \\
\hline Energy from food & $.08^{* *}$ & -0.02 & $.40^{* *}$ & -0.03 & $.63^{* *}$ & $.84^{* *}$ & $-.25^{* *}$ & $.08^{* *}$ \\
\hline Hot beverages (g) & $.48^{* *}$ & $.50^{* *}$ & 0.01 & $.49^{* *}$ & $.05^{*}$ & $.11^{* *}$ & -0.01 & $.48^{* *}$ \\
\hline Milk (g) & $.25^{* *}$ & $.26^{* *}$ & 0.00 & $.27^{* *}$ & 0.04 & $.21^{* *}$ & $.27^{* *}$ & $.25^{* *}$ \\
\hline Fruit juice (g) & $.09^{* *}$ & $.06^{*}$ & $.13^{* *}$ & $.06^{*}$ & $.11^{* *}$ & $.08^{* *}$ & $.11^{* *}$ & $.09^{* *}$ \\
\hline Caloric soft drink (g) & -0.01 & 0.01 & $-.08^{* *}$ & 0.03 & $-.06^{*}$ & $.15^{* *}$ & $.20^{* *}$ & -0.01 \\
\hline Diet soft drink (g) & $.16^{* *}$ & $.16^{* *}$ & $.05^{*}$ & $.15^{* *}$ & $.06^{*}$ & $.06^{*}$ & -0.03 & $.16^{* *}$ \\
\hline Alcohol (g) & $.44^{* *}$ & $.50^{* *}$ & $-.12^{* *}$ & $.52^{* *}$ & $-.19^{* *}$ & $.17^{* *}$ & $.76^{* *}$ & $.44^{* *}$ \\
\hline Bottled water (g) & $.21^{* *}$ & $.18^{* *}$ & $.14^{* *}$ & $.18^{* *}$ & $.12^{* *}$ & 0.03 & 0.01 & $.21^{* *}$ \\
\hline Tap water (g) & $.43^{* *}$ & $.40^{* *}$ & $.18^{* *}$ & $.39^{* *}$ & $.16^{* *}$ & -0.01 & $-.05^{*}$ & $.43^{* *}$ \\
\hline $\begin{array}{l}\text { Variety of beverages consumed } \\
\text { in day (out of } 8 \text { ) }\end{array}$ & $.34^{* *}$ & $.32^{* *}$ & $.14^{* *}$ & $.32^{* *}$ & $.12^{* *}$ & $.16^{* *}$ & $.28^{* *}$ & $.34^{* *}$ \\
\hline
\end{tabular}

* Water from food and beverages.

observed in this study. On days alcohol was consumed, total water intake was $42 \%$ higher among men and $24 \%$ higher among women (data not shown).

Combined classification for low vs. high water intake (TWI-2) Men and women with water intakes below the EFSA AI $(2.5 \mathrm{~L}$ or $2.0 \mathrm{~L})$ who also had a low water to energy ratio $(<1.0)$ were classified as having low water intake in both an absolute and a relative sense (low TWI-2), whilst those who were above the cut offs for both definitions were classified as high TWI-2. The remaining adults were excluded from the analysis. On this basis approximately $23 \%$ of all women and $33 \%$ of all men hade low TWI-2, while $45 \%$ and $41 \%$, of men and women had high TWI-2. Men with high TWI-2 had slightly higher EI than men with low TWI-2 (2470 vs. $2287 \mathrm{kcal} / \mathrm{d})$, but

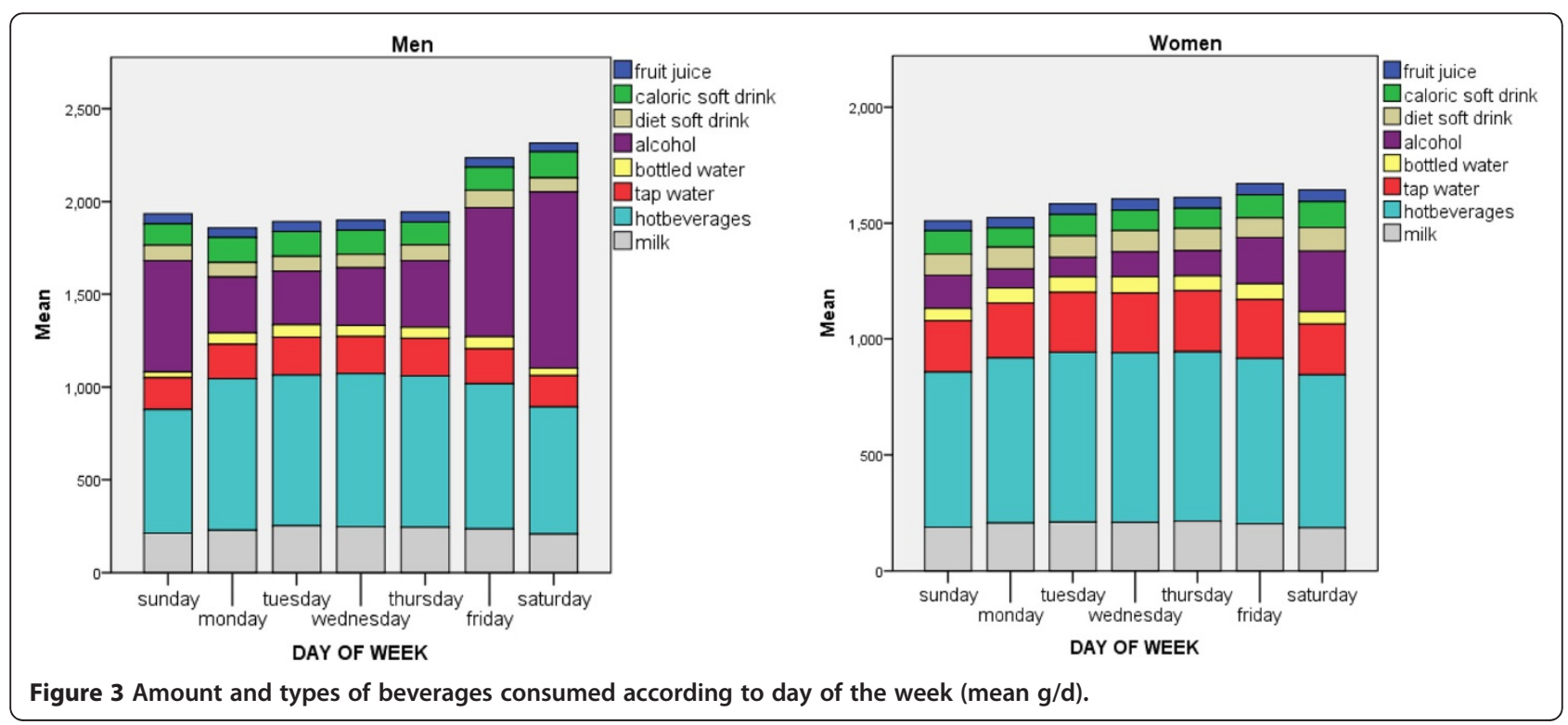



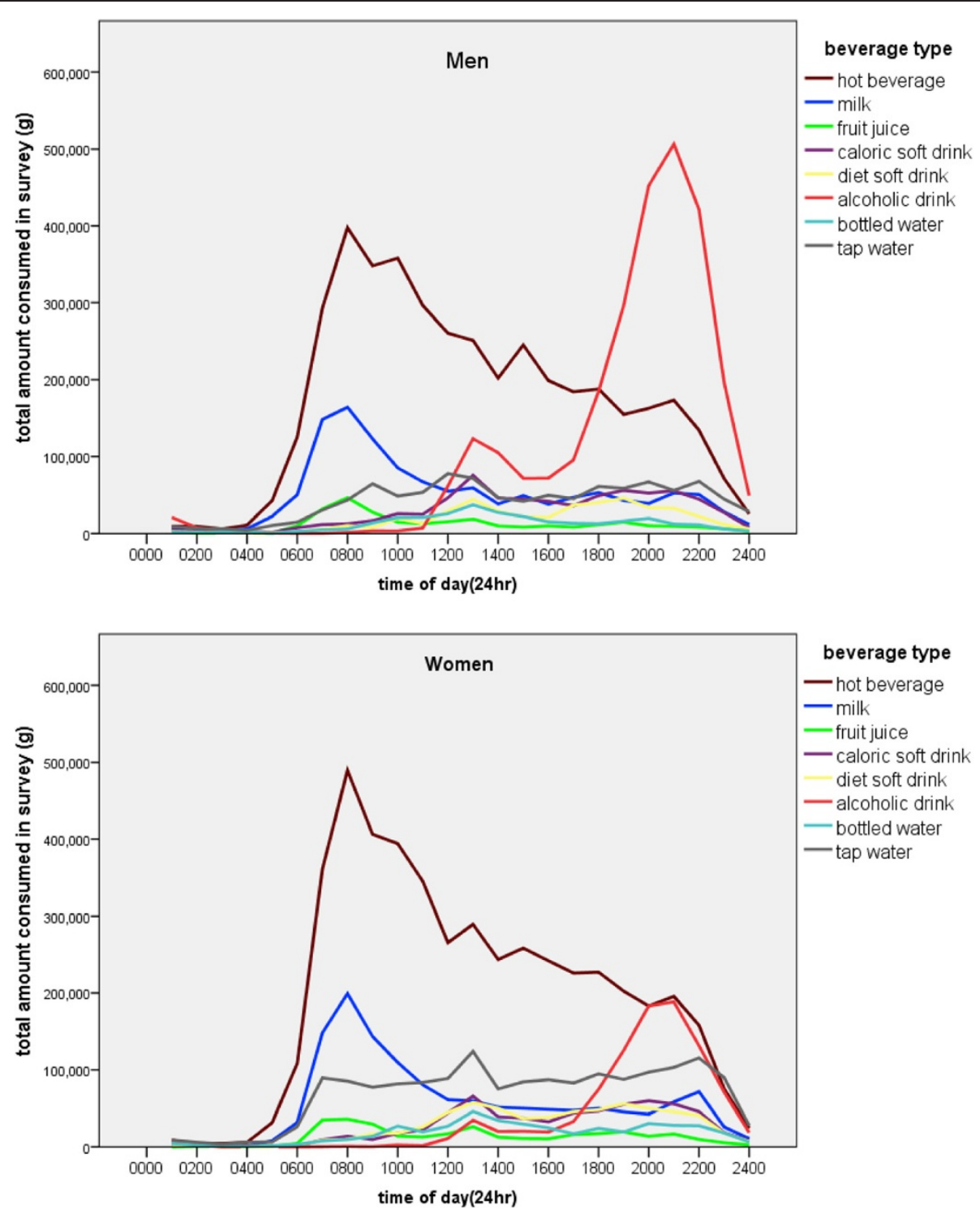

Figure 4 Time of consumption by beverage type.

this was due to a higher contribution from alcohol (330 vs. $99 \mathrm{kcal} / \mathrm{d})(\mathrm{P}<0.0001)($ data not shown). For women, mean EI was not significantly different between the TWI-2 categories (1753 vs. $1716 \mathrm{kcal} / \mathrm{d} ; \mathrm{P}=0.32)$. On a proportional basis, women with low TWI-2 drank significantly less water and hot beverages, while men consumed less water and alcohol compared with the high TWI-2 adults. Adults with low TWI-2 had diets of higher energy density and this applied to foods as well as beverages.

\section{Estimated effect of caloric beverages (liquid calories)}

There was no difference in total energy intake when beverage calories increased at the expense of food calories
(Table 6); (i.e. "a calorie is a calorie"). This is one interpretation of the liquid calories hypothesis. However, a more relevant question for public health is to what extent replacing caloric beverages by non-caloric beverages would help reduce energy intake and (possibly) reduce obesity.

To address this, our first models (Table 7) included 7 covariates (sex, age, bodyweight, smoking, dieting, physical activity and misreporting) and also total beverage intake, hence mathematically equivalent to substituting caloric beverages (sum of milk, fruit juice, caloric soft drinks and alcoholic beverages) for an equal weight of non-caloric beverages (hot beverages excluding milk, diet drinks, tap water and bottled water). The predicted 
Table 5 Beverage consumption according to time of day, by age group

\begin{tabular}{|c|c|c|c|c|c|c|c|c|c|c|}
\hline \multirow[b]{3}{*}{$\begin{array}{l}\text { Mean amount of beverages } \\
\text { (g/d) consumed between }\end{array}$} & \multicolumn{5}{|c|}{ Male } & \multicolumn{5}{|c|}{ Female } \\
\hline & \multicolumn{3}{|c|}{ Age group } & \multirow[b]{2}{*}{ Total } & \multirow[b]{2}{*}{$\begin{array}{l}\text { Significant } \\
\text { differences }\end{array}$} & \multicolumn{3}{|c|}{ Age group } & \multirow[b]{2}{*}{ Total } & \multirow[b]{2}{*}{$\begin{array}{l}\text { Significant } \\
\text { differences }\end{array}$} \\
\hline & $<35 y(A)$ & $35<50 y(B)$ & $50 y+(C)$ & & & $<35 y(A)$ & $\begin{array}{c}35<50 y \\
\text { (B) }\end{array}$ & $50 y+(C)$ & & \\
\hline 0200 to $1000 \mathrm{hrs}$ & 372 & 480 & 538 & 463 & $A<B<C$ & 329 & 443 & 495 & 420 & $A<B<C$ \\
\hline 1000 to $1400 \mathrm{hrs}$ & 415 & 446 & 425 & 430 & $A<B$ & 365 & 374 & 359 & 367 & NS \\
\hline 1400 to $1800 \mathrm{hrs}$ & 365 & 381 & 339 & 364 & $C<B$ & 289 & 321 & 319 & 310 & $A<B, C$ \\
\hline 1800 to $2200 \mathrm{hrs}$ & 648 & 580 & 509 & 581 & $A>B>C$ & 399 & 406 & 343 & 386 & $A, B>C$ \\
\hline 2200 to $0200 \mathrm{hrs}$ & 191 & 190 & 137 & 175 & $A, B>C$ & 121 & 104 & 106 & 110 & $A>B$ \\
\hline Total Beverages & 1991 & 2077 & 1948 & 2012 & $C<B$ & 1503 & 1648 & 1622 & 1593 & $A<B, C$ \\
\hline
\end{tabular}

effect of replacing $100 \mathrm{~g}$ caloric beverages with noncaloric drink was a reduction of $15 \mathrm{kcal}$ (allowing food intake to vary) (Table 7, Model 1). When food energy intake was constrained as constant (i.e. disallowing compensation) the net impact of $100 \mathrm{~g}$ caloric beverages was estimated at $34 \mathrm{kcal}$ (Table 7, Model 2). These estimates are based on the consumption patterns of other adults in the survey with similar patterns.

The second analysis (Table 8) used a within-person change model to address whether a change in an individual's beverage consumption habit on any day was associated with a change in their total energy intake (compared with their 7 day mean). Modelling each beverage separately, with total beverage weight held constant, each of the 4 non-caloric beverages was negatively associated with energy, while the 4 caloric beverages were positively associated with energy (Table 8, Model 3). Combining caloric beverages together, the final models (Table 8 , Models 4 \& 5) gave an estimated effect of $29 \mathrm{kcal}$ per $100 \mathrm{~g}$ of caloric drinks substituted, or $35 \mathrm{kcal}$ if food energy (kcal) was held constant. By comparison, the mean caloric content of the caloric beverages consumed (calculated from the database) was $47 \mathrm{kcal} / 100 \mathrm{~g}$.

\section{Discussion}

Using 12068 days of weighed dietary records from a nationally-representative sample of British adults aged 19 to 64 years, we have quantified total water intakes, and investigated relationships between beverage consumption patterns and water and energy intakes.

Mean TWI was almost identical to the European (EFSA) reference or "adequate intake" (AI) of $2 \mathrm{~L}$ for women and $2.5 \mathrm{~L}$ for men [4]. EFSA determined their AIs from a combination of observed intakes in population groups, with desirable urine osmolarity values and desirable water volumes per energy unit consumed. These AIs only apply to conditions of moderate environmental temperature and moderate physical activity levels; physically active individuals or those working in hot conditions may require more. However, AIs are likely to exceed requirements and cannot predict which individuals are under- or overhydrated in practice. Using more conservative criteria (TWI below AI and TWI <1 g per kcal of energy intake) approximately $33 \%$ of men and $23 \%$ of women were classified as having low water intakes. These may be at greater theoretical risk of poor hydration, but may actually be appropriately hydrated if they have low volumes of water loss due to their individual physiology, environment and physical activity. In our opinion a value of $1 \mathrm{~g}$ water per kcal energy requirement (rather than energy intake) would seem an appropriate basis for a UK recommended mean water intake, and has the utility of broad applicability across age/sex groups. However, it would be helpful to attempt to specify a confidence interval around this mean to avoid confusion and misuse.

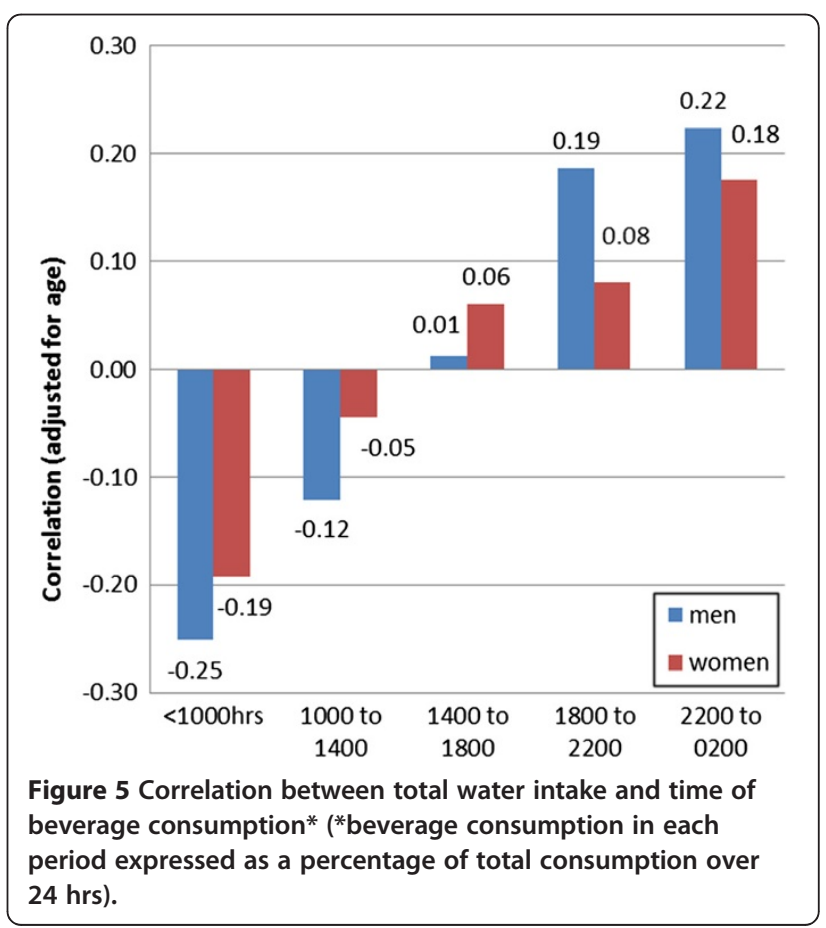


Table 6 Total energy intake according to relative contribution of beverages vs. food

\begin{tabular}{lllllll}
\hline & & \multicolumn{6}{c}{ \%energy from beverages (quintiles) } \\
\cline { 2 - 7 } & & $<=\mathbf{9}$ & $\mathbf{1 0 - 1 2}$ & $\mathbf{1 3 - 1 6}$ & $\mathbf{1 7 - 2 1}$ & $\mathbf{2 2 +}$ \\
\hline ENERGY - kcal & mean & 1953 & 1940 & 1941 & 1969 & 1949 \\
& SE & 20 & 20 & 19 & 19 & 20
\end{tabular}

(estimated marginal means, adjusted for covariates: age Sex, current smoker, weight, physical activity, mis-reporting , dieting status).

Beverages supplied 75\% of TWI for adults in this British study. This is consistent with other estimates $[4,7,8]$, but the proportion may vary considerably between individuals and between populations. As we have shown, beverage consumption (and water intake) is not evenly spread throughout the day, but tends to be concentrated

Table 7 Regression model estimating change in energy intake associated with adding caloric beverages in place of non-caloric beverages

\begin{tabular}{lcccc}
\hline Model 1 & B & P value & \multicolumn{2}{c}{$\begin{array}{c}\text { 95\% Confidence } \\
\text { interval for B }\end{array}$} \\
\cline { 2 - 5 } & & & Lower & Upper \\
\cline { 2 - 5 } (Constant) & 1040 & $<0.0001$ & 852 & 1227 \\
Sex -female & -371 & $<0.0001$ & -414 & -328 \\
Age (years) & -1.6 & 0.044 & -3.1 & 0.0 \\
current smoker & -63 & 0.001 & -100 & -25 \\
weight (kg) & 7.2 & $<0.0001$ & 6.0 & 8.4 \\
Dieting & -67 & 0.005 & -114 & -20 \\
Activity (MET) & 147 & $<0.0001$ & 104 & 190 \\
Valid reporter & 659 & $<0.0001$ & 617 & 700 \\
Total beverages $(100 \mathrm{~g} / \mathrm{d})$ & 11 & $<0.0001$ & 10 & 12 \\
4caloricbeverages $(100 \mathrm{~g})^{*}$ & 15 & $<0.0001$ & 10 & 20 \\
\hline Model 2, Keeping Food Constant & & & \\
\hline
\end{tabular}

\begin{tabular}{|c|c|c|c|c|}
\hline & \multirow[t]{2}{*}{ B } & \multirow[t]{2}{*}{$P$ value } & \multicolumn{2}{|c|}{$\begin{array}{l}\text { 95\% Confidence } \\
\text { Interval for B }\end{array}$} \\
\hline & & & Lower & Upper \\
\hline (Constant) & 62 & 0.01 & 15 & 109 \\
\hline Sex-female & -20 & 0.001 & -31 & -8 \\
\hline Age (years) & 0.4 & 0.023 & 0.6 & 0.8 \\
\hline current smoker & 16 & 0.001 & 7 & 26 \\
\hline weight (kg) & 0.2 & 0.241 & -0.1 & 0.5 \\
\hline Dieting & 1 & 0.826 & -10 & 13 \\
\hline Activity (MET) & -4 & 0.513 & -14 & 7 \\
\hline Valid reporter & 40 & $<0.0001$ & 28 & 53 \\
\hline Food (kcal) & 0.97 & $<0.0001$ & 0.96 & 0.98 \\
\hline Total beverages (100 g) & 2 & $<0.0001$ & 1 & 3 \\
\hline 4caloricbeverages $(100 \mathrm{~g})^{*}$ & 34 & $<0.0001$ & 33 & 36 \\
\hline
\end{tabular}

* 4caloric beverages = sum of milk, fruit juice, caloric soft drinks and alcoholic drinks. in the evening. This leaves the possibility that some adults may be relatively overhydrated in the evening/ nighttime and under-hydrated in the morning. As alcoholic beverages were a significant source of water and energy, especially among men, and were strongly associated with evening consumption, men who drink alcohol may be particularly vulnerable. TWI can be increased by offering more variety in beverages [26]. However, if such an intervention is to benefit public health, it is important that the additional fluid is consumed when needed, and does not result in excessive water intake, unwanted effects on energy balance, or inadequate nutrition.

Table 8 Within-person change Model: estimated change in energy intake associated with beverage substitution

\begin{tabular}{lcccc}
\hline Model 3 Estimated effect of substituting each beverage type * \\
\hline & B & $\begin{array}{c}\text { P } \\
\text { value }\end{array}$ & \multicolumn{2}{c}{$\begin{array}{c}\text { 95\% Confidence } \\
\text { interval for B }\end{array}$} \\
\cline { 2 - 5 } Change in: & & & Lower & Upper \\
\cline { 2 - 5 } Hot beverages (100 g) & -15 & $<0.0001$ & -18 & -12 \\
Milk (100 g) & 15 & $<0.0001$ & 8 & 22 \\
Fruit juice (100 g) & 25 & $<0.0001$ & 15 & 35 \\
Caloric soft drink (100 g) & 23 & $<0.0001$ & 18 & 27 \\
Diet soft drink (100 g) & -15 & $<0.0001$ & -20 & -9 \\
Alcohol (100 g) & 17 & $<0.0001$ & 15 & 19 \\
Bottled water (100 g) & -21 & $<0.0001$ & -27 & -15 \\
Tap water (100 g) & -31 & $<0.0001$ & -35 & -28 \\
\hline
\end{tabular}

Model 4 Estimated effect of caloric beverages replacing non-caloric beverages

Change in total beverages

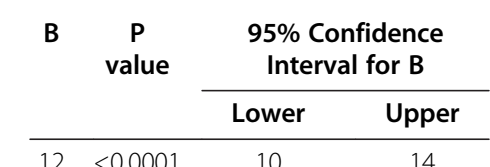

(100 g)

Change in caloric beverages

$12<0.0001 \quad 10$

14

\section{(100 g)}

Model 5 Estimated effect of caloric beverages replacing caloric beverages, holding food energy constant

\begin{tabular}{lcccc} 
& B & $\begin{array}{c}\text { P } \\
\text { value }\end{array}$ & \multicolumn{2}{c}{$\begin{array}{c}\text { 95\% Confidence } \\
\text { Interval for B }\end{array}$} \\
\cline { 3 - 5 } & & & $\begin{array}{c}\text { Lower } \\
\text { Bound }\end{array}$ & $\begin{array}{c}\text { Upper } \\
\text { Bound }\end{array}$ \\
\cline { 2 - 4 } $\begin{array}{l}\text { Change in food energy } \\
\text { (100 kcal) }\end{array}$ & 100 & $<0.0001$ & 99.9 & 101 \\
$\begin{array}{l}\text { Change in total beverages } \\
\text { (100 g) }\end{array}$ & 1 & $<0.0001$ & 0.9 & 1.8 \\
$\begin{array}{l}\text { Change in caloric beverages } \\
\text { (100 g) }\end{array}$ & 35 & $<0.0001$ & 35 & 36
\end{tabular}
(100 g)

* Model 3 is a composite of 8 regressions, one for each beverage, adjusted for change in total weight of beverages; coefficients express the change in energy intake associated with a change in one beverage type and a corresponding reduction in others, i.e. constant total beverage intake. 
Since our analysis was conducted, $\mathrm{Ng}$ et al. [9] have reported on UK trends in beverage consumption over the past 25 years. There are some differences in methodology between our studies, but their calculation for adults in 2000/2001 (18\% of energy obtained from beverages) compares with our estimate of $16 \%$ (which excluded discretionary sugar). Had we been able to include table sugar added to drinks, we would have seen a small contribution of tea and coffee to energy intake but our overall findings would not have been affected. Between 2000 and 2008/9 the energy intake contributed by beverages (in total) did not change, while sweetened tea and coffee declined and consumption of alcoholic beverages and caloric soft drinks rose, although not significantly [9]. In 2008/9 alcoholic beverages provided $770 \mathrm{~kJ} / \mathrm{d}(184 \mathrm{kcal} / \mathrm{d})$ per capita, and caloric soft drinks (soda and juice drinks) $209 \mathrm{~kJ}$ (50 kcal/d) per capita; hence our conclusions concerning the dominance of alcohol appear to remain valid. According to $\mathrm{Ng}$ et al., TWI increased by approximately 9\% between 2000/2001 and 2008/2009, as people consumed more water as a beverage and more water in food (fruit and vegetables) [9], a trend that may have been influenced by healthy eating campaigns and marketing of bottled water. However, consumption of water, tea and coffee, soft drinks and juice among adults has changed little over the last 3 years (NDNS 2008-2011) [27,28], and plain water consumption in the UK remains lower than among adults in France [11], Canada [29] or America [30]. Consumption habits are particularly well- documented in the US, and NHANES surveys show alcohol providing (only) $115 \mathrm{kcal} / \mathrm{d}$ for adults, while soda /fruit drinks provided $141 \mathrm{kcaL} / \mathrm{d}$ in $2005 / 2006$ [30]. It appears that the main increase in soft drink consumption in the US occurred between the 1970s and the 1990s, and a new study confirms that liquid calories have been falling in the US diet over the past decade, although consumption remains high [31].

The present study demonstrates that well-conducted national surveys such as the NDNS have the potential to yield rich contextual data that can be linked with nutrition and health measures. We found significant variation in consumption by day of the week and by time of day (see Additional file 1: Appendix for supplementary figures), which few other studies have been able to describe in detail. Alcoholic drinks in particular were a major contributor to evening and weekend peaks in beverage consumption. The extent to which timing of drinking occasions relates to overall TWI and EI requires further study. Associations have also been demonstrated between meal patterns and EI, with the suggestion that evening consumption of calories may be more conducive to total energy excess [32]. However these findings may merely reflect the cultural reality of the evening being a time for eating and drinking. Significantly, and possibly for the first time using such data, we have estimated the effect on EI of switching beverage consumption between caloric and non-caloric sources using within-person daily records.

In terms of the limitations of this study we draw attention to the usual caveats on making causal inferences from observational data. Whilst the data are of the highest quality obtainable, and respondents were revisited to check records and probe for missing items and weights, dietary assessment is an imperfect science. Most errors are likely to be in the direction of omission or underestimation (perhaps especially where alcohol is concerned). Errors of overestimation may also have occurred where a drink was spilt or unfinished, although efforts were made to prevent this by asking respondents to weigh leftovers and estimate spills. There is evidence from validation studies that true EI is underestimated by about 20-25\% in the NDNS [33], but to our knowledge no studies have tried to quantify under-reporting of water intake or beverages specifically. Estimates of water intake adequacy based on survey data are likely to suffer from under-estimation also.

In conclusion, a significant proportion of British adults surveyed in 2000/2001 had low TWI, although in the absence of clinical measures this could not be equated with poor hydration status. Further work may be warranted to assess current intakes and to explore correlations with urine volumes, as recommended recently [3]. Soft drinks were not a major source of liquid calories among these British adults, whereas alcohol was more significant. All beverages supplying energy can contribute to higher total EI, but in practice some degree of compensatory underconsumption of other foods or beverages may occur. Mechanistic and experimental studies are required to address directly the satiety effects of beverages, while work is also needed to understand the drivers of beverage consumption, which are not merely physiological but also psychological, social and environmental. Further research based on dietary patterns rather than singular foods or dietary components may help identify unhealthy behaviors and provide better evidenced-based recommendations for adequate fluid intake and optimal beverage consumption.

\section{Additional file}

Additional file 1: Appendix. Time charts of beverage consumption for each day in males and females.

Competing interests

SG has received funding for research and consultancy from a number of food and beverage companies. SS has received funding for research and consultancy from a number of companies that produce drinks. 


\section{Authors' contributions}

SG conceived the project and was responsible for analyzing and interpreting data, drafting and finalizing the paper. SS contributed to interpretation of results and discussion. Both authors read and approved the final manuscript.

\section{Acknowledgement}

This study followed ILSI guidelines relating to financial conflicts and scientific integrity [34]. The sponsors (Coca Cola) had no part in the study design, analysis, interpretation, writing or editing of the manuscript. Conclusions and opinion expressed remain the responsibility of the authors and not of the sponsors or of the Survey funders, contractors or depositors.

We thank Dr Graham Horgan for providing statistical advice.

\section{Funding of survey}

UK government (Food standards Agency, Department of Health).

\section{Funding of secondary analysis}

Industry (Coca Cola).

\section{Author details}

${ }^{1}$ Sig-Nurture Ltd., Guildford, Surrey Gu1 2TF, UK. ${ }^{2}$ School of Sport, Exercise and Health Sciences, Loughborough University, Loughborough LE11 3TU, UK.

Received: 12 April 2012 Accepted: 21 December 2012 Published: 10 January 2013

\section{References}

1. Jequier $\mathrm{E}$, Constant F: Water as an essential nutrient: the physiological basis of hydration. Eur J Clin Nutr 2010, 64:115-123.

2. Benelam B, Wyness L: Hydration and health: a review. Nutr Bull 2010, 35:3-25

3. Popkin BM, D'Anci KE, Rosenberg $\mathrm{H}$ : Water, hydration, and health. Nutr Rev 2010, 68:439-458.

4. EFSA Panel on Dietetic Products, Nutrition, and Allergies (NDA): Scientific Opinion on Dietary reference values for water. EFSA Journal 2010, 8(3):1459. doi:10.2903/j.efsa.2010.1459. Available online: www.efsa.europa.eu [48 pp.]

5. Institute of Medicine, Panel on Dietary Reference Intakes for Electrolytes and Water: Dietary Reference Intakes for Water, Potassium, Sodium, Chloride and Sulfate. Food and Nutrition Board. Washington DC: The National Academies Press; 2005. Available online at http://www.nap.edu/openbook.php? isbn=0309091691.

6. WHO (World Health Organisation): Nutrients in Drinking Water. Geneva: WHO; 2005.

7. Kant AK, Graubard Bl, Atchison EA: Intakes of plain water, moisture in foods and beverages, and total water in the adult US populationnutritional, meal pattern, and body weight correlates: National Health and Nutrition Examination Surveys 1999-2006. Am J Clin Nutr 2009 90:655-663.

8. Gibson S, Gunn P, Maughan RJ: Hydration, water intake, and beverage consumption habits among adults. Nutr Bull 2012, 37:182-192.

9. Ng SW, Ni Mhurchu C, Jebb SA, Popkin BM: Patterns and trends of beverage consumption among children and adults in Great Britain, 1986-2009. Br J Nutr 2012, 108(3):536-551.

10. Becker W, Pearson M: Riksmaten 1997-1998. Dietary habits and nutrient intake in Sweden, The second national food consumption survey. Available at: http://www.slv.se/en-gb/Group1/Food-and-Nutrition/Dietary-surveys1/ Riksmaten-1997-98-Dietary-habits-and-nutrient-intake-in-Sweden.

11. Volatier JL: Enquête INCA (Enquête individuelle et nationale sur les consommations alimentaires, Collection AFSSA). Paris: Lavoisier; 2000.

12. Manz F, Wentz A: Hydration status in the United States and Germany. Nutr Rev 2005, 63:S55-S62.

13. Toegepast Natuurwetenschappelijk Onderzoek (TNO) Voedselconsumptiepeiling (VCP-3).: Zeist; 1998.

14. Hu FB, Malik VS: Sugar-sweetened beverages and risk of obesity and type 2 diabetes: epidemiologic evidence. Physiol Behav 2010, 100:47-54.

15. Woodward-Lopez G, Kao J, Ritchie L: To what extent have sweetened beverages contributed to the obesity epidemic? Public Health Nutr 2011, 14(3):499-509. Epub Sep 232010
16. Gibson S: Sugar-sweetened soft drinks and obesity: a systematic review of the evidence from observational studies and interventions. Nutr Res Rev 2008, 21:134-147.

17. Mattes RD, Shikany JM, Kaiser KA, Allison DB: Nutritively sweetened beverage consumption and body weight: a systematic review and meta-analysis of randomized experiments. Obes Rev 2011, 12:346-365.

18. Cassady BA, Considine RV, Mattes RD: Beverage consumption, appetite, and energy intake: what did you expect? Am J Clin Nutr 2012, 95(3):587-593.

19. Drewnowski A, Bellisle F: Liquid calories, sugar, and body weight. Am J Clin Nutr 2007, 85:651-661.

20. Henderson L, Gregory J, Irving K, Swan G: The National Diet and Nutrition Survey:adults aged 19 to 64 years. Volume 2: Energy, protein, carbohydrate, fat and alcohol intake. TSO, London: Office for National Statistics; 2003.

21. Hoare J, Henderson L, Bates C, Prentice A, Birch M, Swan G, Farron M: The National Diet and Nutrition Survey:adults aged 19 to 64 years. Volume 5: Summary report. TSO, London: Office for National Statistics; 2004.

22. Ruston D, Hoare J, Henderson L, Gregory J, Bates C, Prentice A, Birch M, Swan G, Farron M: The National Diet and Nutrition Survey: adults aged 19 to 64 years. Volume 4:Nutritional status (anthropometry and blood analytes), blood pressure and physical activity. TSO, London: Office for National Statistics: 2004

23. Bornhorst C, Huybrechts I, Hebestreit A, Vanaelst B, Molnar D, Bel-Serrat S, Mouratidou T, Moreno LA, Pala V, Eha M, et al: Diet-obesity associations in children: approaches to counteract attenuation caused by misreporting. Public Health Nutr 2012, :1-11. doi:10.1017/S1368980012004491. Epub. 19 Oct 2012

24. Nielsen SJ, Popkin BM: Changes in beverage intake between 1977 and 2001. Am J Prev Med 2004, 27:205-210.

25. Black AE: Critical evaluation of energy intake using the goldberg cut-off for energy intake:basal metabolic rate. A practical guide to its calculation, use and limitations. Int J Obes Relat Metab Disord 2000, 24:1119-1130.

26. Mullie P, Aerenhouts D, Clarys P: Demographic, socioeconomic and nutritional determinants of daily versus non-daily sugar-sweetened and artificially sweetened beverage consumption. Eur J Clin Nutr 2012, 66:150-155.

27. Bates B, Lennox A, Bates C, Swan G: National Diet and Nutrition Survey. Tables from Years 1 and 2 (combined) of the Rolling Programme (2008/2009 - 2009/10) London: Department of Health; 2011. available online at http://www.dh.gov. uk/en/Publicationsandstatistics/Publications/PublicationsStatistics/DH_128166.

28. Bates B, Lennox A, Prentice A, Bates C, Swan G: National Diet and Nutrition Survey: Headline Results from Years 1, 2 and 3 (combined) of the Rolling Programme 2008/09 - 2010/11. Department of Health; 2012. available online at http://transparency.dh.gov.uk/2012/07/25/ndns-3-years-report/.

29. Garriquet D: Beverage consumption of Canadian adults. Health Rep 2008 19:23-29.

30. Popkin BM: Patterns of beverage use across the lifecycle. Physiol Behav 2010, 100:4-9.

31. Welsh J, Sylvetsky AC, Vos M: Trends in beverage consumption among US children and adolescents, 1999 to 2008. Obesity 2011, 19(SUPPLEMENT 1). abstract 103-OR, S69.

32. de Castro JM: The time of day of food intake influences overall intake in humans. J Nutr 2004, 134:104-111.

33. Rennie $\mathrm{KL}$, Coward A, Jebb SA: Estimating under-reporting of energy intake in dietary surveys using an individualised method. Br J Nutr 2007 97:1169-1176.

34. Rowe S, Alexander N, Clydesdale FM, Applebaum RS, Atkinson S, Black RM, Dwyer JT, Hentges E, Higley NA, Lefevre M, et al: Funding food science and nutrition research: financial conflicts and scientific integrity. J Nutr 2009, 139:1051-1053.

doi:10.1186/1475-2891-12-9

Cite this article as: Gibson and Shirreffs: Beverage consumption habits "24/7" among British adults: association with total water intake and energy intake. Nutrition Journal 2013 12:9. 